\title{
Armando Pereira da Câmara, o professor ${ }^{*}$
}

\author{
Sérgio Almeida de Figueiredo*
}

Ao receber a incumbência do professor Plínio de Oliveira Corrêa, coordenador deste seminário comemorativo do centenário de nossa Faculdade de Direito, para discorrer, neste dia, sobre Armando Pereira da Câmara, o Professor, julguei, a princípio, ser uma tarefa relativamente fácil visto ter sido eu seu aluno no $1^{\circ}$ ano do curso jurídico em Introdução à Ciência do Direito, e, no $5^{\circ}$ ano, em Filosofia do Direito, além de, por três vezes já haver publicado artigos sobre sua atividade como docente, e, ainda, por havê-lo sucedido na cátedra como titular da disciplina de Filosofia do Direito.
A primeira publicação, em 1976 sobre o "Conselho de Justiça".'

A segunda, em 19.04.80 - no Correio do Povo p. 12 - "Aula do Professor Armando Câmara". Descrição da figura do professor e seu modo de ministrar uma aula. ${ }^{2}$

A terceira na edição comemorativa do centenário de nascimento de Armando Câmara, desta vez sobre o que ensinava Armando Câmara. ${ }^{3}$

Mas achei que seria mais adequado não prestar um depoimento ou um comentário doutrinário como das três vezes anteriores com o intuito de registrar à atual geração de alunos e aos pósteros, a figura do mestre insigne,

\footnotetext{
"Palestra proferida no Ciclo de Conferências sobre: "Influência da Faculdade de Direito da UFRGS na Política e nas Letras Jurídicas", promovido no período de abril a julho de 1999.

"* Professor aposentado da Faculdade de Direito da UFRGS.

1 CONSELHO de Justiça. Revista Chronos, Caxias do Sul: v. 8, p. 12.

2 AULA do Professor Armando Câmara. Correio do Povo, Porto Alegre, 19 abr. 1980, p. 12. 3 Revista Direito e Justiça, Porto Alegre: v. 20, n. 19, p. 9-13, 1998.
} 
e sim, desta vez, colocar em contraposição a sua pedagogia e as pedagogias vigentes neste século que se extingue.

Ao tentar enquadrar Armando Câmara numa escola pedagógica, com suas linhas balizadoras, seus métodos, cânones, horários, didáticas préestabelecidas, e toda a sua previsibilidade, veio-me à mente o que disse o nosso Mário Quintana sobre o poeta - "enquadrá-lo numa escola é condená-lo à prisão perpétua".

Senti, só então, quando o recuo já não era possível, as dimensões da tarefa que o professor Plínio Corrêa me impusera, com a sua proverbial afabilidade e que foi por mim presunçosamente aceita.

É que as escolas pedagógicas hodiernas, e são muitas, segundo a lição que busquei em Fernando Becker, em sua Epistemologia do Professor, são redutíveis a três grandes grupos. ${ }^{4}$

O primeiro, reúne as centradas no professor, tendendo a valorizar as relações hierárquicas, em nome da transmissão do conhecimento. Seria, segundo Paulo Freire, A pedagogia dos oprimidos que denunciaria uma "educação domesticadora" que produziria "ditadores, por um lado, e indivíduos subservenientes, anulados em sua capacidade criativa, por outro." 5
No segundo elenco, sob pretexto de enfrentar o autoritarismo do primeiro modelo, estão as que centralizam no polo do aluno - atribuindo-lhe qualidades que ele não tem, tais como o domínio sistematizado dos conteúdos, e a capacidade de abstração suficiente. Sobre esses Georges Snyders, em Para onde vão as pedagogias não-diretivas?, mostra "quão autoritária pode ser uma sala de aula sob tal regime."

O terceiro grupo abriga os que constróem uma pedagogia centrada na relação professor-aluno e tende a desabsolutizar, dialetizando: "Nenhum dos pólos dispõe de hierarquia". Nas palavras de Becker, "o professor traz a sua bagagem e o aluno também". Destaca-se a importância do conteúdo, a experiência da vida e a capacidade de construir conhecimentos. Não seria o professor portador de um saber absoluto a ser transmitido ao aluno ignorante por definição.?

O suporte deste enfoque encontra-se no psicologismo de Piaget. Chama-se teoria da assimilação ou construtivista.

A rigor, a divisão das doutrinas em três grupos, reflete, num primeiro momento, a divisão do pensamento do homem moderno, obrigado a optar ou pelo racionalismo-idealista ou pelo empirismo-realista. São os dois fulcros

4 BECKER, Fernando. Epistemiologia do professor. 6.ed. Petrópolis: Vozes, 1993.

5 Ibidem, p. 9.

6 Ibidem, p. 10.

7 Ibidem, p. 10-11. 
percorridos pela filosofia moderna que de um lado com Pascal, Descartes, Spinoza, Leibniz, o racionalismo apriorista, e de outro com Bacon, Hobbes, Locke, Hume, com o conhecimento a posteriori do empirismo e as versões kantianas quando se acentuou a divisão. De um lado o idealismo hegeliano e, de outro, o positivismo de Comte.

$\mathrm{Na}$ primeira posição, certamente não vamos encontrar Armando Câmara. Autoridade, sim, pela sua sabedoria, pelo que ensinava, e como ensinava, mas sem autoritarismo, dialogando.

Dele disse, a tal respeito, o seu exaluno professor José Fabrício Leiria: "O notável professor casava num gesto o talento, a bravura e a bondade. Com sua personalidade singular, sabia despertar a sensibilidade dos moços, para mostrar-lhes os caminhos da justiça da paz e da ordem com liberdade. Liberdade que o empolgava e haveria de ser a pedra angular de todo o seu magistério. Pois do esplendor de sua cátedra de Filosofia do Direito mostrava aos jovens que, sem o império de uma ordem com liberdade, o direito não pode se realizar na sua plenitude, visto que o direito é algo que se radica na natureza racional e social do homem. E, desta forma, ele é descoberto pela razão e realizado pela liberdade. Logo, a falta de liberdade asfixia a justiça e desvitaliza a ordem jurídica. ${ }^{8}$

Não só o professor Leiria, mas outro seu ex-aluno também depôs em Contribuição à Filosofia Jurídica Refiro-me a José Japur, advogado nos auditórios de Porto Alegre: "Seu forte estava na oralidade socrática. A forma escrita imobilizava ou amortalhava os conceitos numa prisão asfixiante. A oralidade era a sua preferida, mesmo porque amava o diálogo com seus discípulos. Espírito aberto e fraternal, apesar de aposentado, ministrou de 1969 a 1974 na Faculdade de Direito da Universidade Federal do Rio Grande do Sul, um Curso de Especialização em Filosofia do Direito. Fui seu aluno e orgulho-me disso. Muito aprendi, guardando de memória seus conceitos, alguns como verdadeiras pérolas da sabedoria universal.

Também Lenine Nequete, que fazia votos de que Câmara viesse a cumprir uma tarefa soberba (falar da gênese do conceito de Justiça) "para que não se perca a extensão e riqueza de uma idéia, a tal ponto que dela se poderia deduzir, inclusive uma autêntica Filosofia da História que, apelando para a instância última da Teologia, resolveria em si a autonomia da liberdade (sem a qual não se compreende o homem) e do curso necessário dos acontecimentos profanos (sem o qual não há história) visto que o homem só se realiza na

8 Ver Estudos, v. 35, n. 19, p. 33-35, 1975. 
medida em que transcende, isto é, na medida em que, visualizando intelectualmente os valores, encarnaos, concretiza-os em bens culturais, modelando-se a si e ao mundo (e é isto a história, um sucessivo aproximar-se da fundação do Reino de Deus)."

Notem que estes são depoimentos de ex-alunos, que já como pessoas realizadas profissionalmente em vários ramos das carreiras jurídicas e professores renomados sentavam-se todos os sábados na "Sala 5" para ouvir suas lições, sempre dialogadas.

Logo, não cabe a pedagogia do professor Câmara no primeiro grupo antes referido, e não há como enquadrá-lo entre os que lecionam sem considerar o aluno, antes os entusiasma, ou não se explicaria a referência feita por tantos discípulos.

Não seriam suas lições capazes de produzir indivíduos subservientes, anulados em sua capacidade criativa constituindo-se no que Paulo Freire chamaria de pedagogia dos oprimidos.

Também não podemos enquadrá-lo no segundo grande grupo em que se reúnem as doutrinas pedagógicas que se centralizam no pólo-aluno supondo nele uma capacidade de retenção suficiente e o domínio sistematizado de conteúdo, como se este pudesse aflorar espontaneamente, negando aos mesmos alunos os seus conhecimentos, de forma egoísta. O já citado Georges Snyders, diz o professor Becker, que nos mostra quão autoritária pode ser uma sala de aula em que vigora tal pedagogia. Jules Celma, é ainda mais enfático ao denunciar o quanto de autoritarismo pode-se praticar sob uma pedagogia não-diretiva. O suporte deste modelo é dado, na psicologia, pela chamada "Escola Nova".

Armando Câmara considerava os alunos e os convidava ao debate. Não era professor de ficar ouvindo passivamente o que pudesse aflorar de uma manifestação caótica. Era ele quem tomava a iniciativa e provocava a atenção e a participação dos alunos.

Tive, alhures, a oportunidade de escrever: "Ali estava um homem austero, sábio, de porte ascético, resultado de uma vida voltada ao estudo, à pesquisa, à reflexão, à oração."

Mas nós, seus alunos, que caminhávamos com ele para a "Sala 5", sabíamos que daí a pouco toda esta potencialidade acumulada seria enérgica e generosamente atualizada. Seria na aula que ele daria vazão a toda a sua comunicabilidade. Eram seus alunos os seus confidentes, aqueles a quem transmitia todas as suas tensões, os resultados dos seus estudos, e os transmitia com gosto, com elegância, com eloqüência e com incrível vivacidade.

9 NEQUETE, Lenine. Advertência. Rev. Estudos, abr.jjun. 1971, p. 1-2. 
Ninguém adivinharia que aquele homem fechado e circunspecto pudesse se transfigurar a tal ponto, de, não raro, arrancar aplausos ou formidáveis gargalhadas com seus ditos inesperados cheios de sabedoria e humor.

A terceira posição, a construtivista, ou da assimilação, é de cunho fenomenalista. Aparece como superadora do empirismo de uma e do apriorismo de outra corrente, para anular a separação a que se condena o homem moderno chamado a optar sempre entre racionalismo e empirismo, entre o individualismo e o coletivismo, entre o liberalismo e o socialismo.

Desperta esta teoria certa simpatia porque, após, vários séculos de uma separação intransponível entre os dois modos de pensar, e, por conseqüência, de agir, surge uma corrente filosófica que apaga o traço que limita um e outro hemisfério do pensamento e do agir humano.

Heidegger, voltando a Heráclito, gerou uma gama de opções filosóficas que se refletiram nas diferentes áreas do conhecimento como culturalismo e o egologismo no Direito e o construtivismo, versão pedagógica do estruturalismo na lingüística.

O construtivismo pretende superar a dicotomia em que se dividiu o pensamento filosófico e, por conseqüência, o pedagógico. Certo, já é alguma coisa, mas não vai além de construir um homem para a vida como ela é.

A isso diz Câmara:
Não se cogita que o mestre poderse-ia resignar a uma pedagogia centrada num humanismo realista, de inspiração antropocêntrica, renunciando à tarefa de transcender a média humana, resignando-se a formar o homem para a existência tal como ela é, não como deveria ser.

Ser homem é querer ser mais do que humano. Aliás, todo o humanismo, se não parte, chega, sempre, a esse voto supremo, a essa aspiração última: a de evasão, pelo homem, dos limites, que parecem intransponíveis, de sua natureza, [...]. [...] Todos os autênticos pedagogos o foram, porque padeceram dessa tortura de traduzir, na vida real, esse anseio, ideal do sobre-humano.

Não poderia Câmara -, que fez parte de uma geração de professores que superaram o próprio positivismo que informara a política do Rio Grande e a orientação nas primeiras décadas desta Faculdade -, fazer parte do elenco dos empiristas do tipo comtiano ou dos racionalistas do tipo hegeliano, e, pelo que recém se disse não o encontraremos também no fenomenalismo que informa o terceiro grupo. Este supera aquela linha divisória, extinguindo-a e Câmara a considera e a supera, transpondo.

Não se conformando com este modo de pensar porque não é anulando a diferença entre substância e acidente, e, por consequiência a separação do mundo das idéias do mundo sensível, e, ainda por conseqüência, não distinguindo entre o universal e o individual, entre a forma e a matéria, que vamos superar a divisão a que está 
condenado o homem moderno. Mas admitindo um e outro campo, superando, transpondo, vale dizer transcendendo. Transcender é partir do real para o ideal, por abstração.

Voltamos novamente ao ponto de partida: fixar a arte de ensinar de Armando Câmara, já que dificilmente se encontra similar nos dias que correm.

Alguma coisa do seu jeito de ser e de ensinar lembra Sócrates e sua maiêutica. Era de seu feitio provocar o diálogo. E como provocava! E o fazia com singular senso de humor. Sentiase que ao ensinar ele transmitia um extraordinário entusiasmo sem limites de horário, ao sabor de um improviso que não se desgarrava em outros temas porque, ele próprio, portava uma linha de pensamento à qual era fiel em suas palavras e atitudes. $\mathrm{E}$ isto o impedia de contradizer-se e o fazia manter uma conformidade com a meta a que se propunha.

Tinha-se a impressão de que a própria "Sala 5", a de sua preferência, já não era limitada pelas paredes vetustas deste edifício feito por homens que pensavam grande.

A atmosfera que ele transmitia tem algo a ver com o jarddim de Academus de Platão, com as alamedas do peripato onde ensinava Aristóteles com o pórtico de Zenão ou do jardim de Epicuro.

Ensinava dialogando e dizia isto perguntando e respondendo: "Será o homem o mestre do homem?"

Realmente, ensina-se ou se busca ensinar tudo e sobre todas as coisas.
Vivemos em permanente estado inflacionário de atividades docentes. Tudo é escola e tudo é docência.

Se a vida é convívio, e convívio é diálogo, então, conviver é ensinar, pois, em todo o diálogo se oculta a pretensão de uma aula, traveste-se a intenção, consciente ou subconsciente, de afirmar uma tese, de fundamentar uma opinião, de comunicar um ponto de vista.

Isso explica seu método socrático, pois sem conversar com os alunos não poderia transmitir ensinamentos e sem ouvi-los não poderia medir as suas tensões e suas dificuldades.

Mas deixemos que o próprio Câmara diga o que fez, e como fez, já que num discurso em que agradecia o título de Professor Insigne outorgado pelo Instituto da Ordem dos Advogados, em 14.08.1968, após a saudação do prof. Galeno Vellinho de Lacerda, quando lhe deram o título.

Alguns excertos deste discurso já foram citados e constam da coleção Pensadores Gaúchos, Obras Escolhidas - Armando Câmara, coletados com esmero pelo prof. Luis Alberto de Boni e estão entre as páginas 77 e 81 da edição da Edipucrs "[...] o panorama da ação docente é imenso: mede-se sua amplitude pelo número de matérias ou objetos cognoscíveis e, portanto, ensináveis, pelos diferentes graus dos conhecimentos que se quer transmitir, pelos inúmeros objetos formais, ponto de enfocamento ou centros de perspectiva, através dos quais se pode 
contemplar a realidade. E para designar o agente destas múltiplas e díspares operações pedagógicas, o homem usa a palavra mestre."

[...] quer-se designar, com a palavra mestre, o agente de um tipo de operação criadora, não apenas duma visão intelectual das coisas - o que seria instrução - mas, ainda, de uma forma de vida, de uma determinada modelagem de ser, de uma estilização integral da personalidade humana - 0 que seria educação.

O mestre não só instruiria, mas educaria, começando pelo seu estilo de vida, uma forma de viver que, acima de tudo, guardava conformidade com o que se ensinava.

$\mathrm{O}$ aluno merece esta coerência. $\mathrm{O}$ que Câmara ensinava, vivia. E ninguém duvidava de sua sinceridade.

Assim, ele podia revelar as suas opiniões pessoais, seja sobre os fatos da vida, revelando-se como cristão católico ou como político. Maragato, está visto.

Não feria ninguém tomando esta posição. O que queria dizer é que o aluno não poderia viver sem a conformidade do pensar e do agir. Esta a grande lição. E isto o fazia respeitar as outras opiniões desde que vindas com a marca da sinceridade.

Aqui está o ponto nevrálgico da questão. Não basta enfocar a relação professor-aluno, e que cada um traga a sua bagagem para daí construir alguma coisa.

Piaget escapa do empirismo por senti-lo insuficiente mas não absolutiza, não transcende; apela então, sem sair do mundo fático, para a carga genética de milhões de anos que influem no comportamento. E esta carga genética por si e em movimento, e as demais experiências do aprendizado, incluindo aí a experiência de vida e o conhecimento sistematizado do professor, "dialetizando", consistiria na estrutura na qual se movimenta a pedagogia. Mas não sai daí.

Armando Câmara propõe mais. Professor e aluno precisam crescer. $\mathrm{Da}$ parte do professor uma clareza de exposição que não desminta sua vida, antes a confirme, para passar esta segurança ao aluno a fim de que ele atinja os fins de sua vida.

Pergunta e responde ele: "Será uma tal tarefa obra humana?"

Há um paradoxo, inexoravelmente incluso, na missão atribuída ao mestre. Exige-se dele, que obviamente é homem, que seja agente de uma tarefa sobre-humana.

Há também uma clara resposta às pedagogias acima agrupadas e referidas. E cita Aristóteles: "Não é bom propor ao homem apenas o humano."

É importante notar que toda esta pedagogia, hoje singular, que é a volta arejada das disputationes que fez nascer as universidades, isso não fazia dele um fanático ou um intransigente.

Ouvia com incrível paciência, e usava sempre a arma da persuasão, e, acima de tudo, o apostolado de sua vida. Havia uma coerência entre o que pensava, vivia e ensinava. 
A sua religiosidade não o afastava dos não-crentes, antes os aproximava enquanto havia neles a sincera vontade da busca da verdade, e neste ponto ele e adversários se identificavam.

Ouvi um bispo argentino, em Calafate, nos cumes andinos da Patagônia, dizer que em matéria de religião é preciso ter idéias claras e convicções firmes, pois quem tem convicções firmes e idéias claras pode se dar ao luxo de ser condescendente.

O fanático é sempre intransigente e avesso ao diálogo, por isso agride e se nega a ponderar.

Quem tem convicções firmes e idéias claras ouve, considera, compreende, releva e, sobretudo, no caso de Câmara, dialoga. Enfim, convive.

Ele revelava seu pensamento crítico e sua condição de cristão católico, com naturalidade e isso transparecia no seu discurso, porque este era coerente com suas idéias e "não queria perder a sua carteira de identidade ideológica."

Mesmo a sua profissão de político, maragato, transparecia, nas suas lições mas nunca deixou de referir e discutir honestamente idéias de adversários.
Esta honestidade dava uma autenticidade ao que pregava, e dava a grande lição do exemplo de vida que isto é comum a todo o homem de bem.

No discurso referido, ao agradecer o título de Professor Insigne que lhe outorgaram os advogados, fez enfatizar que o único mestre era o Verbo de Deus. "Existe um Deus pedagogo? Este Mestre existe, malgrado a cegueira dos que buscam ignorá-lo, malgrado a responsabilidade dos que recusam recebê-lo. Ele veio concluir sua obra criadora, fazendo-se mestre e educador do homem".

Mas diz também: "só não usurpam o título de mestre aqueles homens que prolongam sua ação salvadora".

"Portanto, sua pedagogia está centrada em algo transcendente, abarca professor e aluno, contando, tudo em função de algo mais alto".

E assim se refere ao único Mestre

que é Mestre do meu pensamento, que é legislador de minha ação, que será juiz de minha existência, que já declina no horizonte do tempo, e de cuja infinita piedade eu espero a imortalização do meu ser. 